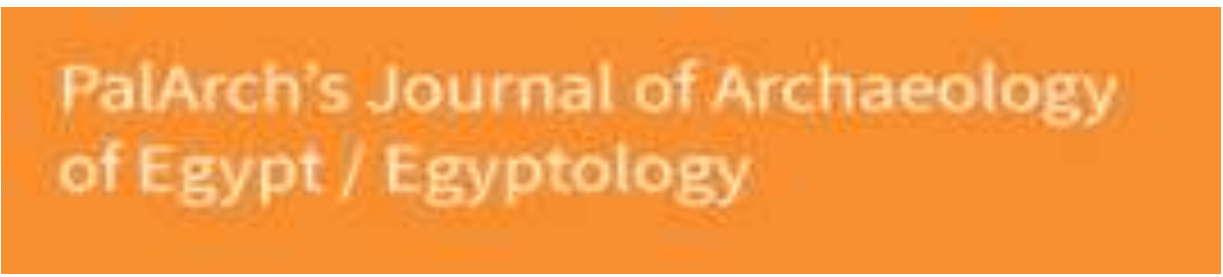

\title{
THEORIES OF CONTINENTAL DRIFT
}

\author{
Vishvantha D Veeraiyan ${ }^{1}$, Dr. Deepak Nallasamy $V^{2}$ \\ ${ }^{1}$ Scholar, Pupil Global School, Chennai. \\ ${ }^{2}$ Professor, Department of Prosthodontic, Saveetha Dental College and Hospital, SIMATS, \\ Saveetha University, Chennai. \\ Corresponding Author: ${ }^{2}$ dir.acad.sac@gmail.com
}

Klemi Subiyantoro,Ina Primiana Sagir,Aldrin Herwany,Rie Febrian. Competitive Strategy Model And Its Impact On Micro Business Unit Of Local Development Banks In Jawa-- Palarch's Journal Of Archaeology Of Egypt/Egyptology 17(4), 470-484. ISSN 1567-214x

Keywords: Continental, Drift.

\begin{abstract}
:
Continental drift is the process of continental plates moving. The movement is very slow, and it might take even years to show the impact on the Earth. The movement depends on gravity, convection drift, and plate formation. Gravity impacts the movements as the mantle (The layer below the crust) is always spinning because of gravity and the plates are located on the mantle. Convection drift impacts on the movement because convection drift is a cycle of melting and cooling of rocks in the mantle which can slowly impact the movement of the plate. Plate formation also affects the way the plates move as the new plates formed pushes the nearby plates causing movement.
\end{abstract}

\section{INTRODUCTION}

The concept of continental drift can be best visualized by the change in position of the tectonic plates; this change is very slow, spanning over 100's of millenia. Therefore most of our evidence can only be found in paleo archaeological features [1] [1]. On an average tectonic plates only move around 2 inches per year [2]. This speed can vary based on numerous factors as previously mentioned (craters, continental fractions, etc) [3] [3]. The tectonic plate includes the lithosphere and part of the mantle. They float on the inner layer of the earth known as the asthenosphere. The thermal stress of the asthenosphere can affect the speed of plate movement [4]. It is assumed that the asthenosphere behaves like a viscous fluid that causes the tectonic plates to slide over [5]. 
The idea of continental drift was first proposed by Alfred Wegener (1924), and it was supported by Alexander Du Toit (1936) and Lester King. However this was strongly opposed by Jeffreys H (1924), Walter Bucher, Charles Drake, Maurice Ewing Meyerhoff (1970) [6] [6]. It was Bullard, Everett and Smith [7], who provided the first conclusive evidence that proved that South America and Africa were united millions of years ago.

The argument around plate tectonics was so problematic that many geographers lost their career even in the 1970 [8], if they spoke against the dominant theoretical group who believed plate tectonics was impossible. In this article we are going to analyse the types of continental drift, its causes, and how science overcame conventional ego.

\section{HISTORY OF CONTINENTAL DRIFT THEORY}

Thesaurus Geographicus(1596) [9] was the first person to notice the similarity between the coastlines of western Africa, western Europe, and the eastern Americas. He proposed earthquakes tore the continents apart.

In 1924, Alfred Wegener [10]was the first person in the 19th century to observe that the West coast of Africa and the East Coast of South America fit like a jigsaw puzzle. Alfred Wegener was a famous German meteorologist who proposed the theory of continental drift, however his theory was rejected by all the famous geologists of his time. Even though he provided abundant evidence, he was not able to explain the method on continental movement.

Alfred Wegener gave 5 principle evidence to support his theory. The first evidence was the fossil of the freshwater reptile called mesosaurus [11]that was found in the South American tip and African tip. Since a freshwater animal cannot swim across the Atlantic Ocean, Wegener hypothesized that the tips of both South American and African continents must have been together when the animal was alive.

The second evidence was based on the fossil of the fern Glossopteris [12] that was found in the Indian, Australian, South American, Antarctic and African continents. He argued that the fern seeds could not have floated across the Atlantic and Indian Oceans to reach the five subcontinents. Ferns usually prefer tropical climates indicating that Antarctica was not frozen in that era.

The third evidence Alfred Wegener employed to prove his theory was the presence of glacial grooves [13] [13]in the Indian, Australian and the African continents. He also showed that the glacial grooves aligned across the continents if they were put together.

The fourth piece of evidence that Wegener wielded was the alignment of the North American and the European mountain ranges as if they were part of a single mountain range. He also proved that the mountains were of a similar age of formation [14] [14]. 
The final puzzle of evidence was that the continental coastlines lined up to form a single landmass which he called pangea. Pangea means "All Earth" in Greek.[10]

Even though it was not his occupation, he tried his best to prove that there was continental drift, he even published a book about continental drift and today he is respected as a great scientist. Since Wegener was not able to prove his theory the concept of continental drift was rejected till late 1960. In 1965 Bullard, Everett and Smith [7] [7] proved the presence of continental drift .

It was in this decade that humans began exploring the ocean floor and mapping it. They observed massive trenches and rifts extending from the North to South Atlantic. On both sides of the rift, researchers observed fresh bedrock formation, on further analysis they proved that the alternating bands of magnetism show that the bedrock was formed during the recent polar shift [15]. This evidence turned the geological world upside down as everybody started to realise that Alfred Wegener was correct all this while.

Even after Bullards famous publication many scientists continued to strongly oppose the continental drift theory. Most of the opposition were residual to the initial rejection of Wegners theory by famous geologists like Jeffreys H (1924), Walter Bucher, Charles Drake, Maurice Ewing Meyerhoff (1970) [6] [6]. Geologists like Bruce.H [16]planted black flag masts to show his opposition. Maurice Ewing waged a strong warfare against continental drift. He fought until his death in 1974. After this the concept of continental drift became more widely accepted.

\section{CURRENT EVIDENCE ON CONTINENTAL DRIFT}

The Geologists of the present day have plenty of devices like LiDAR [17], SONAR [18], Satellite mapping to accurately measure plate tectonics. We now have an excellent understanding of the various components of continental drift such as Divergents, Convergents, Transforms.

Divergent plate boundary [19] occurs when 2 plates move away from each other. The landforms often created are rift valleys, volcanoes, etc. An example would be how the Atlantic plate pushes away and South America. 


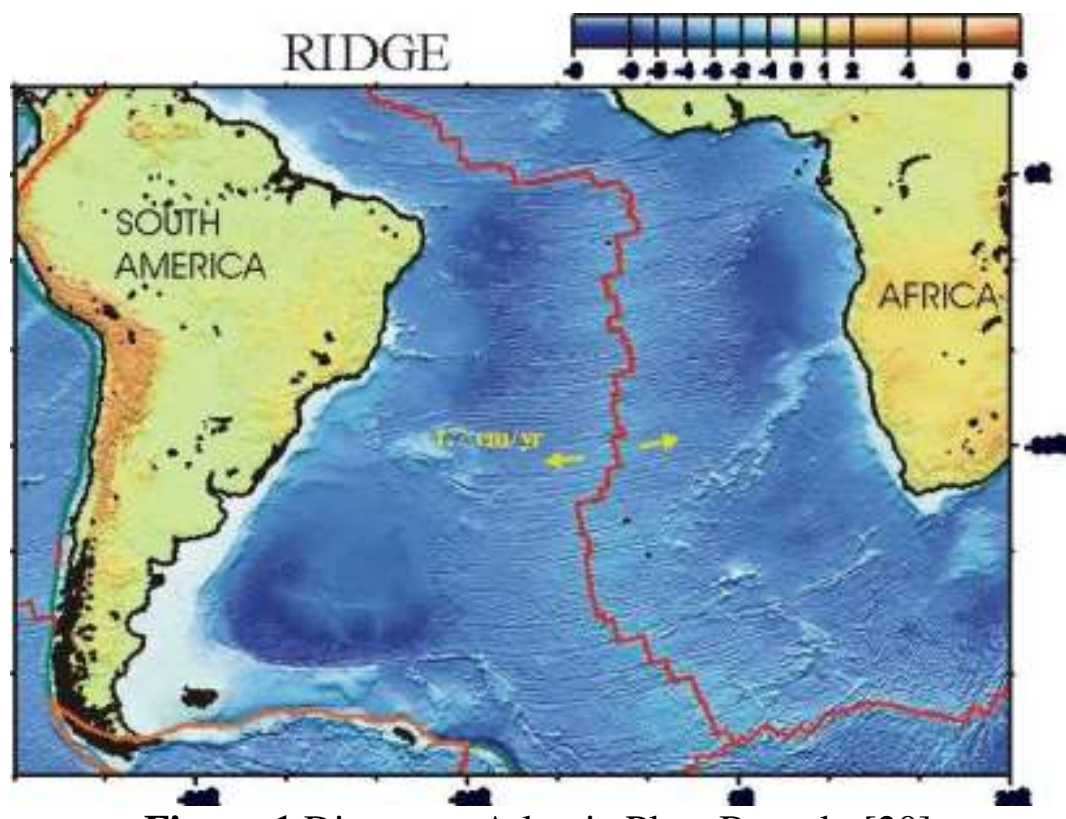

Figure 1 Divergent Atlantic Plate Boundar[20]

Convergent plate boundary is one in which 2 plates collide with each other [21]. This movement often creates mountains, and when subdued volcanoes, etc. An example would be how the Indian subcontinent is colliding with the Asian plate creating the Himalayas.

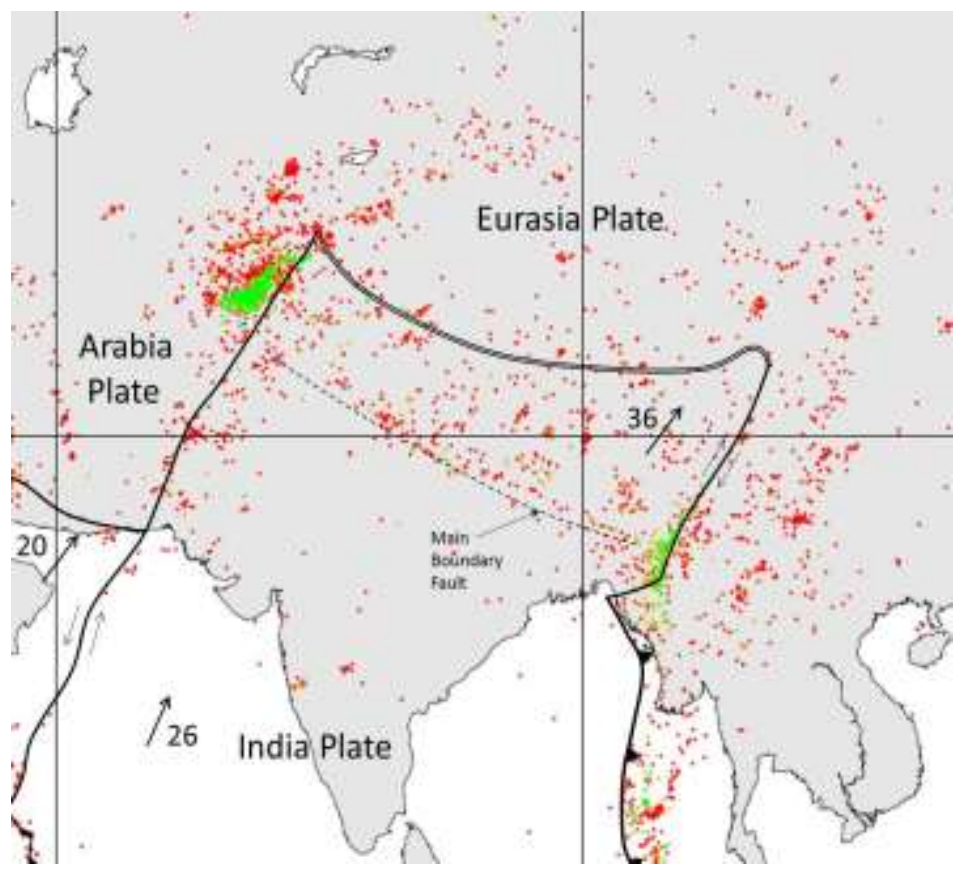

Figure 2 Indian Eurasian Plate Boundar[22]

Transform boundary [23] is when 2 plates scrape past each other. This movement often causes earthquakes and fault lines. An example of this movement is S.t Andreas fault. 


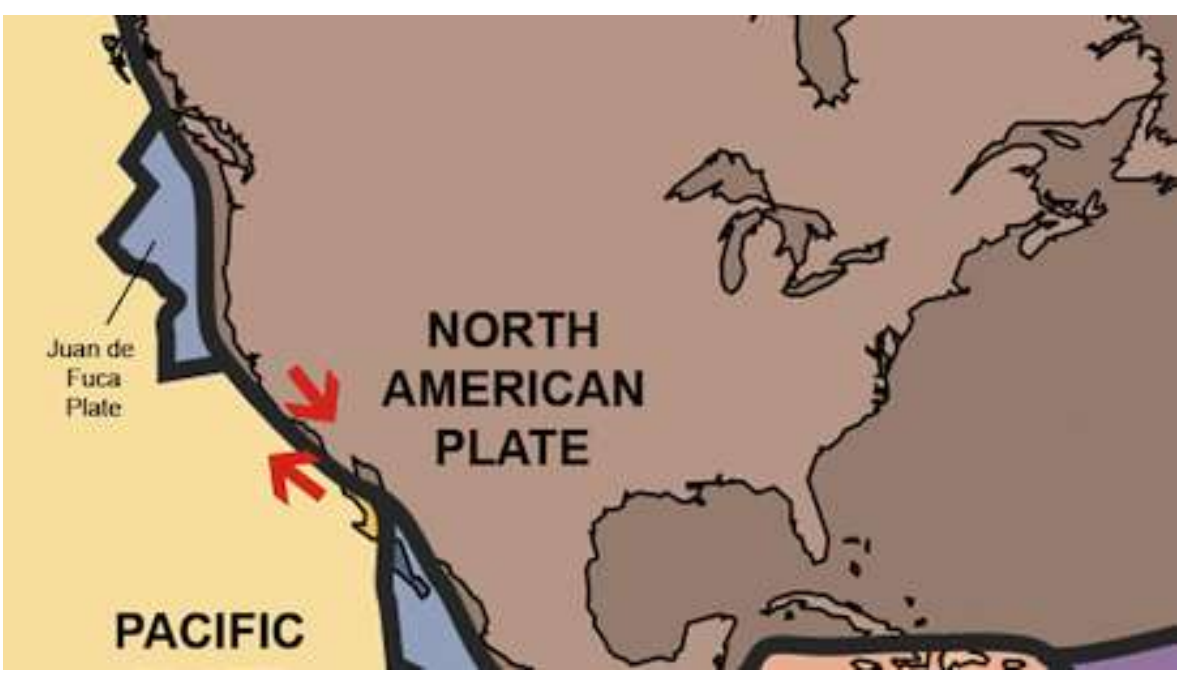

Figure 3 Transform Plate Boundary St. Andreas Fault Line.[24]

\section{CONCLUSION}

In this article we have successfully described the history, theories and the current knowledge of continental drift. This science has fundamentally changed our understanding of evaluation, climate change and overall geology of our planet. It is a good starting point for students to begin research on continental drifts.

\section{REFERENCE}

Nishiwaki C, Uyeda S. Accretion Tectonics and Metallogenesis. Accretion Techtonics in the Circum-Pacific Regions 1983:349-55. https://doi.org/10.1007/978-94-009-7102-8_25.

Zahirovic S, Dietmar Müller R, Seton M, Flament N. Tectonic speed limits from plate kinematic reconstructions. Earth and Planetary Science Letters 2015;418:40-52. https://doi.org/10.1016/j.eps1.2015.02.037.

Speed LLSRC, Sloss LL, Speed RC. Relations of Cratonic and ContinentalMargin Tectonic Episodes: ABSTRACT. AAPG Bulletin 1973;57. https://doi.org/10.1306/83d90c91-16c7-11d7-8645000102c1865d.

Melosh HJ. Plate motion and thermal instability in the asthenosphere. Tectonophysics 1976;35:363-90. https://doi.org/10.1016/00401951(76)90076-7.

Harper JF. Asthenosphere flow and plate motions. Geophysical Journal International 1978;55:87-110. https://doi.org/10.1111/j.1365246x.1978.tb04749.x.

Meyerhoff AA. Continental Drift, II: High-Latitude Evaporite Deposits and Geologic History of Arctic and North Atlantic Oceans. The Journal of Geology 1970;78:406-44. https://doi.org/10.1086/627538.

Bullard EC. Fit of the Continents around the Atlantic. Science 1965;148:664.

Dewey JF. A harbinger of plate tectonics: a commentary on Bullard, Everett and Smith (1965) "The fit of the continents around the Atlantic." Philos 
Trans A Math Phys Eng Sci 2015;373. https://doi.org/10.1098/rsta.2014.0227.

Ortelius A. Thesaurus geographicus. 1596.

Wegener A. The Origin of Continents and Oceans. 2020.

Kay M. Continental Drift in North Atlantic Ocean. North Atlantic-Geology and Continental Drift 1969. https://doi.org/10.1306/m12367c66.

Radforth NW. The Ancient Flora and Continental Drift. Continental Drift 1966:53-70. https://doi.org/10.3138/9781487595678-006.

Oreskes N. To Reconcile Historical Geology with Isostasy: Continental Drift. The Rejection of Continental Drift 1999. https://doi.org/10.1093/oso/9780195117325.003.0009.

Osberg PH. Lower Paleozoic Stratigraphy and Structural Geology, Green Mountain-Sutton Mountain Anticlinorium, Vermont and Southern Quebec. North Atlantic-Geology and Continental Drift 1969. https://doi.org/10.1306/m12367c50.

Deutsch ER. The Rock Magnetic Evidence for Continental Drift. Continental Drift 1966:28-52. https://doi.org/10.3138/9781487595678-005.

Heezen BC. The Rift in the Ocean Floor. Scientific American 1960;203:98110. https://doi.org/10.1038/scientificamerican1060-98.

Kaltenbacher E, Costello D, Carder K. Compact Optical Imager for Real-time, 3-D Range, Intensity and Fluorescence Mapping of the Ocean Floor 2006. https://doi.org/10.21236/ada612266.

Hansen RE. Mapping the ocean floor in extreme resolution using interferometric synthetic aperture sonar. 2019 International Congress on Ultrasonics 2019. https://doi.org/10.1121/2.0001058.

divergent plate boundary. Dictionary Geotechnical Engineering/Wörterbuch GeoTechnik 2014:397-397. https://doi.org/10.1007/978-3-642-417146_42828.

[Notitle]n.d.

https://cimss.ssec.wisc.edu/sage/geology/lesson2/images/concepts_fig1 5.gif (accessed November 12, 2020).

convergent plate boundary. Dictionary Geotechnical Engineering/Wörterbuch GeoTechnik 2014:292-292. https://doi.org/10.1007/978-3-642-417146_34720.

Earle S. Physical Geology. 2019.

transform plate boundary. Dictionary Geotechnical Engineering/Wörterbuch GeoTechnik 2014:1419-1419. https://doi.org/10.1007/978-3-64241714-6_202279.

[No title] n.d. https://study.com/academy/lesson/san-andreas-fault-locationfacts-earthquakes.html (accessed November 12, 2020). 